\title{
Biokatalisator Lipase Dedak Padi Untuk Proses Asidolisis Minyak Tuna Dan Asam Laurat
}

\author{
Wahyuningsih*, Edy Supriyo, dan R.T.D. Wisnu Broto \\ Program Studi, Teknik Kimia Departemen Teknologi Industri, Sekolah Vokasi, Universitas Diponegoro \\ Jl. Prof. Soedarto, Tembalang, Kota Semarang, Jawa Tengah 50275, Indonesia \\ Email: wahyunimachin@gmail.com
}

\begin{abstract}
Abstrak
Lipid terstruktur dengan medium chain fatty acid (MCFA) pada posisi luar dan polyunsaturated fatty acid (PUFA) pada posisi sn-2 memiliki nilai gizi dan absorbsi yang sangat baik. Dalam penelitian ini lipid terstruktur disintesis secara langsung melalui asidolisis enzimatis antara minyak ikan dan asam laurat. Reaksi dikatalisis oleh lipase dedak padi. Tujuan penelitian ini adalah mempelajari perilaku dari reaksi asidolisis enzimatik minyak ikan tuna dan asam laurat, dengan kajian pengaruh biokatalis lipase dedak padi terhadap hasil asidolisis. Target yang ingin dicapai berupa data-data teknis laboratorium untuk perancangan, scale-up dan pengoperasian proses yang meliputi kinetika reaksi, studi produktifitas asam lemak, kondisi operasi yang optimum dan analisa tekno-ekonomi. Hasil penelitian menunjukkan bahwa konsentrasi lipase dan suhu reaksi optimum berturut-turut $10 \%$ dan $50^{\circ} \mathrm{C}$. Rasio mol optimum minyak ikan dan asam laurat adalah 1:10, dihasilkan inkorporasi asam laurat mencapai 62,8 mol\%. Pada waktu inkubasi 12 jam, trigliserida menurun seiring dengan meningkatnya waktu inkubasi, sedangkan digliserida meningkat seiring dengan meningkatnya waktu inkubasi. Pada suhu reaksi di atas $50^{\circ} \mathrm{C}$, trigliserida menurun seiring dengan meningkatnya suhu reaksi. Metode interesterifikasi ini cukup efektif untuk mensintesis lipid terstruktur spesifik. Lipase dapat digunakan dengan baik untuk sintesa Lipid Terstruktur dari minyak ikan tuna dengan asam laurat. Kondisi optimum reaksi adalah pada suhu $50^{\circ} \mathrm{C}$, konsentrasi lipase $10 \%$, perbandingan ratio substrat (Minyak ikan tuna : asam laurat) 1:10 selama $12 \mathrm{jam}$. Profil gliserida dari hasil asidolisis enzimatis adalah 78,1\% trigliserida, 32,2\% digliserida dan $11,9 \%$ monogliserida
\end{abstract}

Kata kunci: Lipid, lipase, dedak padi, minyak ikan tuna

\section{Abstract \\ Lipase Rice Bran Biocatalystator For Asidolysis Process Tuna Oil And Lauric Acid}

Lipid structured with medium chain fatty acids (MCFA) in the outer position and polyunsaturated fatty acid (PUFA) in sn-2 position has excellent nutritional value and absorption. In this study structured lipids were synthesized directly through enzymatic acididisation between fish oil and lauric acid. The reaction was catalyzed by a specific lipase of 1.3 from the tertiary carotid rugose. The aim of this study was to study the behavior of enzymatic acidic reactions of tuna and lauric acid oils, with the study of the effect of rice bran biocatalyst on acidic acid yield. The targets to be achieved are technical laboratory data for design, scale-up and operation of processes including reaction kinetics, fatty acid productivity studies, optimum operating conditions and techno-economic analysis. The results showed that the optimum lipase concentrate and temperature of the reaction were $10 \%$ and $50^{\circ} \mathrm{C}$, respectively. The mole ratio of fish oil and lauric acid was 1:10 in which the incorporation of lauric acid was 62,80\% (mol). Incubation time, $12 \mathrm{~h}$, triglyceride decreased with an increase in incubation time. In contrast, the diglyceride increased with an increase in incubation time. At temperature higher than $50^{\circ} \mathrm{C}$, triglyceride decreased with an increase in reaction temperature. The methode of 
interesterification was proven to be effective in synthezed specific structured lipids. Lipase rice brand, can be used successfully for the synthesis of structured lipids from tuna oil with lauric acid. Optimum reaction temperature is $50^{\circ} \mathrm{C}$, lipase concentration of $10 \%$, the ratio of substrate ratio (tuna fish oil: lauric acid) 1:10 for time incubation 12 hours. Profile gliseride from results acidolysis enzymatic triglycerides were 78.1\%, 32.2\% $11.9 \%$ diglycerides and monoglycerides.

Keywords: lipids, lipase rice brand, tuna fish oil

\section{PENDAHULUAN}

Sintesis lipid terstruktur telah berkembang pesat dalam satu dekade ini dengan memodifikasi lipid terutama untuk meningkatkan sifat fungsional dan nutrisi suatu lemak atau minyak. Lipid terstruktur dengan asam lemak rantai medium $\left(\mathrm{C}_{6}-\mathrm{C}_{12}\right)$ pada posisi luar dan polyunsaturated fatty acid (PUFA) pada posisi sn-2 memiliki nilai gizi dan absorbsi yang sangat baik (Irimescu et al., 2001). Residu rantai medium dengan mudah terhidrolisis di dalam saluran pencernaan menghasilkan asam lemak yang diabsorbsi dengan cepat dan digunakan sebagai sumber energi yang tinggi di dalam tubuh. PUFA terabsorbsi sebagai 2-MG yang paling siap diabsorbsi diantara senyawa turunan PUFA. Lipid terstruktur dengan residu jenuh pada posisi luar dan PUFA pada posisi sn-2 juga lebih tahan terhadap oksidasi (Akoh, 2017).

Lipid terstruktur dapat disintesis dengan interesterifikasi lipid baik secara enzimatis maupun kimia, tetapi metode enzimatis lebih disukai karena enzim memiliki aktivitas biokatalitik yang tinggi dan spesifik. Penggunaan enzim sebagai katalis juga lebih ramah lingkungan dibandingkan secara kimiawi karena limbah dari bahan kimia umumnya berbahaya bagi lingkungan (Akoh, 2017).

Berbagai metode sintesis lipid terstruktur spesifik secara enzimatik telah dilakukan diantaranya melalui pembentukan triasilgliserol (TAG) dari gliserol dan asam lemak (biasanya PUFA) yang dilanjutkan asidolisis dengan asam lemak tertentu, biasanya medium chain fatty acid (MCFA) menggunakan lipase spesifik-1,3 (Irimescu et al., 2001). Sintesis lipid terstruktur spesifik juga telah diteliti dengan melakukan etanolisis pada minyak ikan untuk memperoleh 2-monogliserida yang dilanjutkan dengan esterifikasi dengan asam kaprilat secara enzimatis sehingga diperoleh lipid terstruktur dengan asam kaprilat pada posisi luar dan PUFA pada posisi sn-2 (Irimescu et al., 2002), tetapi proses tersebut kurang ekonomis dan perlu pengendalian proses yang rumit.

Selama ini sintesis lipid terstruktur yang mengandung PUFA dan MCFA umumnya menggunakan asam kaprilat sebagai sumber MCFA, sangat jarang yang menggunakan asam laurat. Metode interesterifikasi antara minyak ikan dengan asam laurat juga belum pernah dilakukan. Pada penelitian ini sintesis lipid terstruktur dilakukan dengan metode interesterifikasi (asidolisis) antara minyak ikan dengan asam laurat yang dikatalisis lipase Mucor miehei yang bersifat spesifik 1,3 sehingga diharapkan asam laurat hanya akan menempati posisi 1,3 dari kerangka gliserol minyak ikan sedangkan PUFA tetap tertinggal dan berada pada posisi sn-2 (Wilis dan Marangoni, 2002)

Namun demikian, harga lipase masih mahal dan mudah terjadi inaktivasi jika dalam bentuk enzim bebas (Irimescu et al., 2001). Maka pada penelitian ini dicobakan lipase konvensional lipase dedak padi yang harganya lebih murah. Pengkajian dilakukan terhadap konsentrasi lipase dedak padi dan suhu reaksi sehingga diperoleh waktu reaksi dan kondisi proses yang optimal. Profil gliserida yang terbentuk diamati.

\section{METODOLOGI}

\section{Interesterifikasi enzimatis minyak ikan dengan asam laurat pada berbagai suhu reaksi}

Waktu reaksi yang optimal kemudian digunakan untuk mengkaji pengaruh suhu reaksi dengan variasi suhu $30,40,50,60$, dan $70^{\circ} \mathrm{C}$. Sebanyak 1,43 gram minyak ikan dicampur dengan 4 gram asam laurat (rasio molar minyak ikan : asam laurat 1:10) dalam erlenmeyer, lalu ditambahkan lipase 0,543 gram candida rugose 
(10\% dari substrat) dan $8,1 \mathrm{ml}$ heksana $(1,5$ kali berat substrat). Erlenmeyer ditutup rapat lalu diinkubasi dalam waterbath shaker pada suhu tervariasi dengan kecepatan 120 rpm selama 12 jam. Setelah direaksikan selama 12 jam, campuran hasil reaksi selanjutnya diperlakukan seperti pada prosedur interesterifikasi enzimatis pada berbagai waktu reaksi. (Irimescu, 2000)

\section{3-8.Preparasi FAME dan analisa penentuan inkorporasi asam laurat}

Preparasi Fame dilakukan sesuai dengan

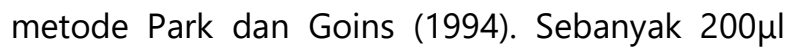
Lipid terstruktur dimasukkan dalam tabung reaksi lalu ditambahkan 50 $\mathrm{ll}$ ( konsentrasi 0,1 $\mathrm{g} / \mathrm{ml}$ ) internal standar asam heptadekanoat, $100 \mu \mathrm{l}$ metilen khlorida dan $1 \mathrm{ml} \mathrm{NaOH} \mathrm{0,5} \mathrm{N} \mathrm{dalam}$ methanol. Kedalam tabung diberi gas Nitrogen sebelum dipanaskan pada suhu $90{ }^{\circ} \mathrm{C}$ selama 10 menit. Setelah dingin ditambah $1 \mathrm{ml}$ aquades dan 200-500 $\mu \mathrm{l}$ heksana dan divorteks untuk mengekstrak methyl ester asam lemak. Fraksi heksana merupakan FAME dan siap dianalisa dengan Gas Kromatografi (GC).

\section{HASIL DAN PEMBAHASAN}

Penelitian pada suhu diatas $50^{\circ} \mathrm{C}$ komponen trigliserida menurun dengan naiknya suhu reaksi. Penurunan tersebut menandakan terjadinya esterifikasi partial komponen trigliserida menghasilkan produk antara digliserida dan monogliserida. Hal tersebut mungkin disebabkan oleh terjadinya migrasi gugus asil yang menyebabkan reaksi asidolisis tidak sempurna (Park dan Goins, 1994). Migrasi asil merupakan berpindahnya asil dari trigliserida dari posisi sn 2 ke posisi sn-1 atau sn-3. Berpindahnya asil tersebut dapat menyebabkan posisi sn-2 kosong sehingga terbentuk digliserida ataupun monogliserida.

Migrasi hasil dapat dipicu oleh tingginya suhu reaksi, kadar air, dan ratio substrat. Selanjutnya juga diketahui bahwa suhu reaksi dan waktu reaksi memicu terbentuknya 1,3diasilgliserol lebuh besar dari pada 1,2 diasilgliserol (Paiva et al., 2000). Dengan terbentuknya 3-diasigliserol maka lipase spesifik 1,3 dari candida rugosa tentu tidak dapat atau sulit untuk mengkataalis asidolisis pada posisi sn2. Dengan demikian, hal tersebut dapat menurunkan komponen trigliserida dan justru meningkatkan digliserida ataupun monogliserida (Subroto, 2007)

Pengaruh konsentrasi lipase terhadap profil gliserida lipid terstruktur ditunjukkan pada Gambar 1.Komponen TG (trigliserida) meningkat seiring dengan meningkatnya konsentrasi lipase (sampai konsentrasi 10\%), hal ini disebabkan karena lipase candida rugose terimmobil sangat spesifik untuk asam laurat (Marangoni, 2002) dan memiliki aktivitas relative rendah terhadap PUFA terutama DHA (Iremecu, 2000). Ketika konsentrasi

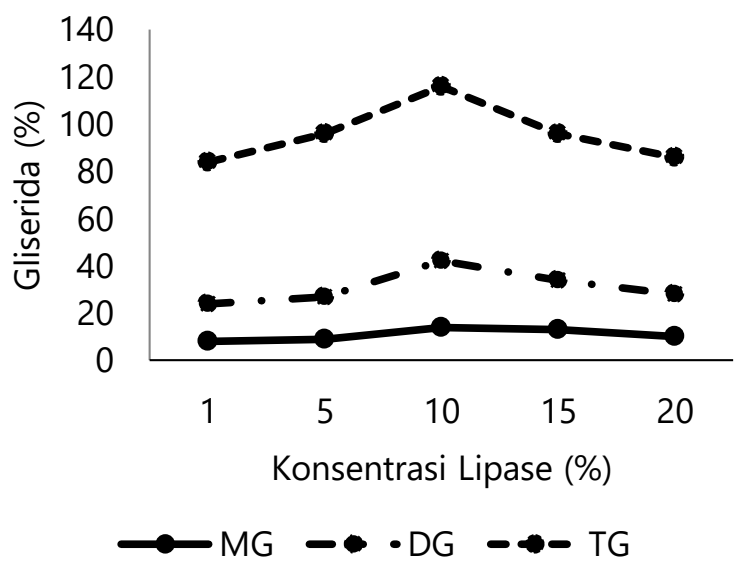

Gambar 1. Grafik Konsentrasi lipase dan Profil gliserida

Tabel 1. Pengaruh suhu terhadap profil Gliserida Lipida Terstruktur

\begin{tabular}{ccccc}
\hline \multirow{2}{*}{ No } & \multirow{2}{*}{ Suhu $\left({ }^{\circ} \mathrm{C}\right)$} & \multicolumn{3}{c}{ \% Gliserida } \\
\cline { 3 - 5 } & 30 & Monogliserida & Digliserida & Trigliserida \\
\hline 1. & 11 & 20 & 60 \\
2. & 40 & 9 & 18 & 69 \\
3. & 50 & 15 & 24 & 78 \\
4. & 60 & 13 & 21 & 62 \\
5 & 70 & 20 & 18 & 58 \\
\hline
\end{tabular}


Tabel 2. Pengaruh \% Konsentrasi Lipase terhadap profil Gliserida Lipida Terstruktur

\begin{tabular}{ccccc}
\hline \multirow{2}{*}{ No } & \multirow{2}{*}{ \% Konsentrasi Lipase } & \multicolumn{3}{c}{ \% Gliserida } \\
\cline { 2 - 5 } & 1 & Monogliserida & Digliserida & Trigliserida \\
\hline 1. & 5 & 8 & 16 & 60 \\
2. & 10 & 9 & 18 & 69 \\
3. & 15 & 14 & 28 & 74 \\
4. & 20 & 10 & 21 & 62 \\
5 & 13 & 18 & 58 \\
\hline
\end{tabular}

lipase rendah maka kecenderungan reaksi berjalan kekanan cukup lemah dan kemampuan lipase untuk mengkatalis untuk proses asidolisis juga relative kecil. Komponen TG (trigliserida) justru menurun jika konsentrasi lipase dinaikkan, hal ini mungkin berkaitan dengan aktivitas lipase yang menurun dengan semakin banyaknya asam lemak bebas. Asam lemak bebas menyebabkan desorbsi air dari interface kemudian mengambil bagian interface air disekitar enzim dan meningkatkan kelarutannya dalam air sehingga akan membatasi masuknya substrat pada interface.Penurunan akivitas lipase tersebut menyebabkan terbentuknya produk intermediate dan reasi asidolisis tidak sempurna (Gandi et al., 2007).

\section{KESIMPULAN}

Lipase candida rugose immobile, dapat digunakan dengan baik untuk sintesa Lipid Terstruktur dari minyak ikan tuna dengan asam laurat.Kondisi optimum reaksi adalah pada suhu $50^{\circ} \mathrm{C}$, konsentrasi lipase $10 \%$, perbandingan ratio substrat(Minyak ikan tuna : asam laurat ) 1:10 selama 12 jam.Profil gliserida dari hasil asidolisis enzimatis adalah 78,1 \% trigliserida,32,2 \% digliserida dan $11,9 \%$ monogliserida

\section{DAFTAR PUSTAKA}

Akoh, C.C. (Ed.). 2017. Food lipids: chemistry, nutrition, and biotechnology. CRC press.

Gandi, J.R., Pence, D.H., Scheinsach, S., D'Amelia, P.R., Klemann, L.P., Wilson, N.H. \& Finkey, J.W., 2007. Review of Triacilglycerols Digestion, Absorption, and Metabolism With Respect to Salatrim Triacylglycerols. Journal of Agricultural and Food Chemistry. 42:473483.

Irimescu, R., Furihata, K., Hata, K., Iwasaki, Y., \& Yamane, T. 2001. Two-step enzymatic synthesis of docosahexaenoic acid-rich symmetrically structured triacylglycerols via 2-monoacylglycerols. Journal of the American Oil Chemists' Society. 78(7):743-748

Irimescu, R., Iwasaki, Y., \& Hou, C. T. 2002. Study of TAG ethanolysis to 2-MAG by immobilized Candida antarctica lipase and synthesis of symmetrically structured TAG. Journal American Oil Chemistry Social. 79(9):879-883

Irimescu, R., Yasui, M., Iwasaki, Y., Shimidzu, N., \& Yamane, T. 2000. Enzymatic synthesis of 1, 3dicapryloyl-2-eicosapentaenoylglycerol.

Journal American Oil Chemists' Society. 77(5):501-506

Marangoni, A.G., 2002. The nature of fractality in fat crystal networks. Trends in Food Science Technology. 13(2):37-47.

Paiva, A.L., Balcao, V.M. \& Malcata, F.X., 2000. Kinetics and mechanisms of reactions catalyzed by immobilized lipases. Enzyme and Microbial Technology. 27(3-5):187-204.

Park, P.W. \& Goins, R.E., 1994. In situ preparation of fatty acid methyl esters for analysis of fatty acid composition in foods. Journal Food Science. 59(6):1262-1266.

Subroto, E. \& Hidayat, C. 2007. Interesterifikasi enzimatis minyak ikan dengan asam laurat untuk sintesis lipid terstruktur. Journal Teknologi Industri Pangan. XII(1).

Wilis, W.M., \& A.G. Marangoni. 2002. Enzymatic Interesterification. In: Food Lipid, Chemistry, Nutrition, and Biotechnology. West Virginia University. 